\title{
A permeability model for the hydraulic fracture filled with proppant packs under combined effect of compaction and embedment
}

\author{
Dong Chen ${ }^{a}$, Zhihui Ye ${ }^{a,}{ }^{*}$ Zhejun Pan ${ }^{b}$, Yingfang Zhou ${ }^{c}$, Jialiang Zhang ${ }^{a}$ \\ ${ }^{a}$ College of Petroleum Engineering, China University of Petroleum (Beijing), Beijing 102200, \\ China \\ ${ }^{b}$ CSIRO Energy, Private Bag 10, Clayton South, VIC 3169, Australia \\ ${ }^{c}$ King's College, University of Aberdeen, Aberdeen AB24 3UE, U.K. \\ *Corresponding author. E-mail address: zhihui.ye@cup.edu.cn
}

\begin{abstract}
Hydraulic fracture is the main flow path for gas transport. The proppants are man-made material that filled in the hydraulic fractures to keep them open and allow gas flow through. The permeability change of hydraulic fracture is controlled by the combined effect of compaction and embedment. In this study, we modeled the proppant embedment as a function of effective stress by a transformed Hertz contact model and a proposed power law model which is analogous to the Oliver-Pharr model. The results illustrate that the power law relationship could better fit the experimental data, because the Hertz model becomes invalid when the embedment is large compared to the proppant size. By incorporating the power law correlation into an existing theoretical permeability model as a function of effective stress, a permeability model for the hydraulic fracture filled with proppant packs under combined effect of compaction and embedment is developed. The new model is able to adequately describe the permeability data of proppant packs confined by rock core slices. Although this study puts forward the theoretical basis of the hydraulic permeability modelling under combined effect of compaction and embedment, more fundamental studies are required to investigate the contact behaviour between the proppant packs and the fracture face under various conditions. Therefore, the permeability model could be further improved by introducing the new advanced proppant embedment correlations.
\end{abstract}

Keywords: permeability; proppant pack; hydraulic fracture; effective stress; embedment 


\section{Introduction}

The shale gas reserves distribute widely around the globe and will supply abundant fossil energy over the coming decades until a switch to renewable energy sources is made (Howarth et al., 2011). However, extraction of this source of unconventional energy is not easy, mainly attributed to the extreme low in-situ permeability (Wang et al., 2009). The hydraulic fracturing technology is required to create a man-made fracture network in shale formation to achieve economic gas production (Holditch, 2013). Hydraulic fracturing is a process of pumping specially engineered fluids at high pressure into the shale formation to create large fractures, which are then propped open with sand or ceramic proppants. The conductivity of hydraulic fractures is significantly increased by filling the fracture channels with multiple layers of proppant particles, also referred as proppant packs. The hydraulic fracture is neither a simply porous media (proppant pack), nor a fractured media, but a composite type of media, the fracture filled with porous proppant packs. The conductivity of hydraulic fracture is not only affected by proppant packs and fracture themselves, but also influenced by their interaction.

A number of experimental studies have revealed that the conductivity of hydraulic fracture can be significantly enhanced by the presence of proppants. Fredd et al. (2000) reported that the permeability varied by at least two orders of magnitude in their experiments while Kassis and Sondergeld (2010) observed that the permeability changed more than 1000 fold. Fredd et al. (2000) stated that the permeability could be proppant dominated by using high-strength proppants. Parker et al. (2005) supplemented that the fracture conductivity was greatly affected by the concentration of the packed proppants in the fracture: higher concentration yielded higher conductivity by virtue of a wider fracture. The initial permeability of the hydraulic fracture is enhanced, but the long term permeability decrease is not optimistic for shale gas production due to its strong stress sensitivity (Wen et al., 2007; Kassis and Sondergeld, 2010; Lee et al., 2010; Gaurav et al., 2012; Suarez-Rivera et al., 2013). This could be a main reason that leads to the productivity falling down for most gas shale plays in the USA (Hughes, 2013). Kassis and Sondergeld (2010) stated that the dependency does not simply obey the cubic pressure dependence law proposed by Walsh (1981).

The proppant embedment has been verified as an important factor that reduces the hydraulic fracture conductivity of fluid. Wen et al. (2007) verified the significant effect of proppant embedment upon the conductivity of fracture through comparing the fluid conductivity of the proppant pack compressed within the steel plateau (without embedment) and the rock (with embedment). The lower conductivity of the proppant pack confined by rock indicated that the proppant embedment played an important role in hydraulic fracture permeability change. Moreover, the proppant embedment was vividly observed by the 
scanning electron micrographs of the Brady sandstone wafers recovered from the quadcell stress tests where the sandstone coupon was in direct contact with proppants (Lee et al., 2010). Alramahi and Sundberg (2012) stated that the hydraulic fracture conductivity loss was controlled by stress, proppant embedment and shale properties. Based on the Hertz contact theory, Khanna et al. (2012) modeled the conductivity of narrow fractures filled with a sparse proppant monolayer, which represents the narrow secondary fractures. The proppant embedment in their work was estimated by the Hertz solution. However, the embedment should be much smaller than proppant size based on the Hertz assumption, which is not strictly consistent with the more general cases in reality.

Modelling of permeability change is complex because the permeability change is not only affected by the effective stress induced proppant packs compaction, but also influenced by the contact stress induced proppant embedment. More recently, Chen et al. (2015) proposed a general permeability model for fractured reservoir rocks including gas shale with irregular and poor connectivity fractures (Slatt and O’Brien, 2011). The model was further verified to be applicable to porous media through theoretical derivation (Chen et al., 2016). The Chen et al. model could be used to evaluate the permeability change of proppant packs under variable effective stress, however, it does not consider the impact of proppant embedment on permeability.

In this study, we modeled proppant embedment on basis of the Hertz contact model and a power law model proposed according to Oliver-Pharr (1992) model respectively. Both models are applied and further developed to describe the experimental data of proppant embedment as a function of effective stress. Their performance is compared and analysed. Then the obtained proppant embedment equation is incorporated into the permeability model developed by Chen et al. (2016). The improved permeability model is applicable to describe the permeability change in the hydraulic fracture filled with proppant packs under combined effect of compaction and embedment. The new model is verified through matching the permeability data of propped fractures. This study aims to obtain a better understanding of the permeability behaviour in the hydraulic fracture with proppant packs under combined effect of compaction and embedment. 


\section{Modelling of proppant embedment}

The hydraulic fracture permeability is mainly affected by proppant pack compaction and embedment. To quantitatively take into account the effect of proppant embedment into the permeability model, a proppant embedment model is required. In this section, the Hertz contact model and a power law model are applied to describe the proppant embedment. The model performance is examined through matching experimental data. The models were originally proposed to relate the contact deformation to the load or force applied. In petroleum industry, stress is frequently used instead of force. The two models are further developed for analysing the proppant embedment as a function of effective stress.

\subsection{Hertz contact model}

According to the classic Hertz contact problem between a rigid sphere and an elastic semiinfinite half-space (Fig. 1), the vertical displacement of the surface at a distance $r$ from the symmetry point of contact is calculated by (Fischer-Cripps, 2007):

$$
\begin{gathered}
u_{z}=\frac{1-v^{2}}{E} \frac{3}{2} p_{m} \frac{\pi}{4 a}\left(2 a^{2}-r^{2}\right) \quad r \leq a \\
u_{z}=\frac{1-v^{2}}{E} \frac{3}{2} p_{m} \frac{1}{2 a}\left[\left(2 a^{2}-r^{2}\right) \sin ^{-1} \frac{a}{r}+r^{2} \frac{a}{r}\left(1-\frac{a^{2}}{r^{2}}\right)^{1 / 2}\right] \quad r \geq a
\end{gathered}
$$

where $v$ and $E$ are the Poisson's ratio and the elasticity modulus of the half-space, respectively, $p_{m}$ is the mean contact pressure and $a$ is the radius of the contact zone which is calculated by (Fischer-Cripps, 2007):

$$
a^{3}=\frac{3}{4} \frac{P R}{E^{*}}
$$

where $P$ is the indenter load, $E^{*}$ is the combined modulus of the indenter and the half-space given by (Fischer-Cripps, 2007):

$$
\frac{1}{E^{*}}=\frac{\left(1-v^{2}\right)}{E}+\frac{\left(1-v^{\prime 2}\right)}{E^{\prime}}
$$

where $E^{\prime}$ and $v^{\prime}$ are the Young's modulus and Poisson's ratio for the sphere. 
For the proppant pack, the mean contact pressure equals to the effective stress $\left(\sigma_{e}=p_{m}\right)$ if the load is fully undertaken by the proppants. The relationship between the mean contact pressure $p_{m}$ (or the effective stress $\sigma_{e}$ ) and the indenter load $P$ is:

$$
p_{m}=\sigma_{e}=\frac{P}{\pi a^{2}}=\left(\frac{4}{3} \frac{E^{*}}{\pi}\right) \frac{a}{R}
$$

The radius of the contact zone $a$ can be calculated by Eq. (5) by knowing the effective stress, the size of proppant and the combined modulus of the indenter (proppant) and the halfspace (shale).

According to Eq. (1), the maximum vertical displacement (the proppant embedment) is attained when $r$ equals to 0 :

$$
u_{z \max }=\frac{3 \pi}{4} \frac{1-v^{2}}{E} \sigma_{e} a
$$

Incorporating Eq. (5) into Eq. (6), we have:

$$
u_{z \max }=\frac{\left(1-v^{2}\right) R}{E E^{*}}\left(\frac{3}{4} \pi \sigma_{e}\right)^{2}
$$

Eq. (7) can be further reduced to:

$$
u_{z \max }=M_{h} \sigma_{e}^{2}
$$

where $M_{h}$ is the composite modulus.

\subsection{Power law model}

In the Hertz contact problem, the depth of penetration or the maximum vertical displacement should be small relative to the radius of the sphere indenter. In a more general case in gas shale reservoir, the proppant embedment is large and the proppant would fully embed in the soft shale (see Fig. 2). Oliver and Pharr (1992) applied a power law relationship between load $(P)$ and indenter embedment $(h)$ :

$$
P=\alpha h^{m}
$$

where $\alpha$ and $\beta$ are fitting parameters from the experiment. 
Imitating the Oliver and Pharr method, we proposed a similar power law correlation between effective stress and indenter displacement:

$$
h=\eta\left(\sigma_{e}\right)^{\lambda}
$$

where $\eta$ and $\lambda$ are the fitting parameters from the experiment.

Moreover, a simple derivation is made in the Appendix to show that Eq. (9) can be reduced to Eq. (10) with specific assumption. In addition, it is noted that the power law model would reduce to the Hertz model when the parameter $\lambda$ equals to 2 .

\subsection{Embedment model verification}

The experimental data from Alramahi and Sundberg (2012) are used to calibrate the proppant embedment model developed. They designed a proppant embedment cell to accurately measure the embedment of proppants into shale samples as they are subjected to increasing loads while submerged in different fluid types. The embedment cell consists of a transparent cylindrical tube where shale samples are placed. Samples are submerged in a water based fluid containing $3 \% \mathrm{KCl}$ to reduce clay swelling for 24 hours before each test is performed then a layer (or multiple layers) of proppant are placed on the sample surface. The shale samples covered a wide range of mechanical properties as well as mineralogical content. In order to avoid proppant crushing under high stresses, high strength proppant bauxite was used in all the experiments. The 20/40 mesh proppants have a mean particle size of $0.6 \mathrm{~mm}$. After the samples were prepared and submerged overnight, axial loading was slowly increased up to 68.9 MPa while deformations were continuously recorded.

A metal loading ram was used to load the shale-proppant stack in a servo-controlled load frame and two Linear Variable Differential Transformers (LVDT) were used to measure the deformation as the axial load was increased. The proppant embedment was obtained by subtracting shale sample deformation (estimated using elastic theory) and apparatus deformation (determined by a separate with rigid metal sample) from the total recorded deformation. Shale sample of small thickness of $7.6 \mathrm{~mm}$ were used in these tests to minimize the sample deformation contribution to the total deformation.

Two models, the Hertz model expressed as Eq. (8) and the power law model expressed as Eq. (10), are verified by the experimental data of proppant embedment in shale specimens. The least squares fitting with Microsoft Excel Solver is used to manage the data fitting (Brown, 2001; Chen et al., 2014). 
Fig. 3 illustrates that the power law correlation could better describe the proppant embedment in shale samples with a wide range clay contents from 10 to 52\%, though a slight deviation of the modelling results to the experimental data (except for the case with $29 \%$ clay content). Generally, the shale sample with high clay content has lower stiffness. Unfortunately, the curvature of the experimental data is far from the squared correlation depicted by the Hertz model. The power index for the power law model is less than 1 for all the samples tested.

In addition, it is observed in Fig. 4 that the matching parameter $\eta$ tends to increase with the clay content. Although no obvious correlation has been found between $\lambda$ and clay content, $\lambda$ distributes relative stably in the range of 0.514 to 0.707 . Overall, the power law model is shown to be capable of describing the proppant embedment as a function of effective stress.

\section{Permeability model development for hydraulic fractures}

The hydraulic fracture filled with proppant packs is a composite fracture system. The permeability of hydraulic fractures depends on fracture properties (aperture, intensity, tortuosity, connectivity and etc.), proppant pack properties (concentration, size and etc.), and their interactions (proppant embedment). During the shale gas production, the permeability in hydraulic fractures can be generally attributed to two main effects: 1) the permeability reduction due to proppant pack compaction with the increase in effective stress (or reservoir pressure drawdown); 2) the permeability decrease induced by proppant embedment, which reduces the fracture aperture. The total hydraulic permeability change is the combined effect of the two factors mentioned above. The power law proppant embedment model that verified in Section 2 is incorporated to improve an existing fracture permeability model. The new model is capable of describe the hydraulic fracture permeability under combined effect of compaction and embedment. The power law proppant embedment model that verified in Section 2 is incorporated to improve an existing fracture permeability model. The new model is capable of describe the hydraulic fracture permeability under combined effect of compaction and embedment.

\subsection{Permeability change due to proppant pack compaction}

The proppant pack permeability reduction due to effective stress change induced compaction can be described by the following equation (Chen et al., 2016):

$$
k_{p}=k_{p 0} e^{-3 \bar{c}_{p}\left(\sigma_{e}-\sigma_{e 0}\right)}
$$


where $k_{p}$ is the permeability of proppant pack, $\bar{c}_{p}$ is the average proppant pack compressibility expressed by Eq. (12), $\sigma_{e}$ is the effective stress and 0 denotes the initial state.

$$
\bar{c}_{p}=\frac{c_{p 0}}{\alpha\left(\sigma_{e}-\sigma_{e 0}\right)}\left(1-e^{-\alpha\left(\sigma_{e}-\sigma_{e 0}\right)}\right)
$$

where $c_{p 0}$ is the initial proppant pack permeability and $\alpha$ is the changing rate of the proppant pack compressibility.

\subsection{Permeability change due to proppant embedment}

Another important factor on the permeability change is the proppant embedment, which results in narrowing hydraulic fracture openings (Fig. 5). According to Chen et al. (2015), the fracture permeability can be expressed as:

$$
k_{f}=D_{f} P_{22} \frac{b^{3}}{12}
$$

where $D_{f}$ is a coefficient related to fracture distribution, $P_{22}$ is the fracture intensity and $b$ is the fracture aperture.

Based on Eq. (13), the permeability change due to the proppant embedment is:

$$
\frac{k_{f}}{k_{f 0}}=\frac{b^{3}}{b_{0}^{3}}=\frac{\left(b_{0}-h\right)^{3}}{b_{0}^{3}}
$$

where $k_{f o}$ is the permeability before embedment, $b_{0}$ is the fracture aperture before embedment (for monolayer proppant condition, $b_{0}$ equals to the proppant diameter), and $h$ is the proppant embedment.

Incorporating Eq. (10), Eq. (14) can be reformed as:

$$
\frac{k_{f}}{k_{f 0}}=\frac{b^{3}}{b_{0}^{3}}=\frac{\left(b_{0}-\eta\left(\sigma_{e}\right)^{\lambda}\right)^{3}}{b_{0}^{3}}
$$

\subsection{Permeability model under combined effect of compaction and embedment}

Synthesize the combined effect of compaction and embedment as discussed individually in Sections 3.1 and 3.2, the permeability model for the hydraulic fracture filled with proppant packs is obtained as: 


$$
k_{h f}=k_{h f 0} \cdot e^{-3 \bar{c}_{p}\left(\sigma_{e}-\sigma_{e 0}\right)} \cdot \frac{\left(b_{0}-\eta\left(\sigma_{e}\right)^{\lambda}\right)^{3}}{b_{0}^{3}}
$$

\section{Permeability model verification}

The experimental data from Wen et al. (2007) are used to calibrate the permeability models developed. In their experiments, two types of proppants commonly used in China (proppants $1 \#$ and 2\#) were used. Moreover, two diameter ranges of each proppant type were examined: one was 20/40-mesh, and the other was 30/60-mesh. The concentration of proppants was 10 $\mathrm{kg} / \mathrm{m}^{2}$, and the closure pressure increased from $10 \mathrm{MPa}$ to $90 \mathrm{MPa}$ with increment of $10 \mathrm{MPa}$ each time. All the experiments were conducted at $120^{\circ} \mathrm{C}$.

Steel platen was used in one conductivity cell to simulate the fracture wall where no embedment could occur, while core slices were used in the other cell to simulate the fracture wall where embedment occurred. The mechanical properties of the rocks used are listed in Table 1. As shown in Table 1, the Young's modulus of the rocks are close to the values for gas shales collected by Sone and Zoback (2013).

The permeability data for proppant pack with steel platen are modeled with Eq. (11). As shown by the dash lines in Fig. 6, the model without considering proppant embedment can properly describe the permeability change for steel confined proppant packs. The parameters used ( $c_{p 0}$ and $\alpha$ ) are listed in Table 2. The two parameters obtained are in the same order of magnitude with those obtained for sandstones, but much smaller than those for shales and coals (Chen et al., 2016). This range of the parameter values ( $c_{p 0}: 0.0011$ to $0.0036 \mathrm{MPa}^{-1} ; \alpha$ : -0.016 to $-0.041 \mathrm{MPa}^{-1}$ ) corresponds to a permeability change within one order of magnitude as observed in Chen et al. (2016) for sandstones. The permeability change in Fig. 6 is consistent with the previous research findings.

The permeability changes under rock core confining condition are modeled with Eq. (16). It is shown in Fig. 6 that the permeability would further reduce by several times once the closure pressure surpasses the critical pressure that ranges from 40 to $50 \mathrm{MPa}$ for these samples studied and the proppant embedment becomes a dominant influencing factor on the permeability drop. Fig. 6 also illustrates that the model could adequately describe the permeability change under the combined effect of compaction and embedment. The size of the proppant pack is $17.8 \mathrm{~cm}$ in length and $3.8 \mathrm{~cm}$ in width. The initial fracture aperture $b_{0}$ is fixed at $1.9 \mathrm{~cm}$ when matching the experimental data for all the four scenarios. The data fitting is achieved by adjusting the two parameters controlling the proppant embedment $(\eta$ 
and $\lambda$ ), the value of which used are also listed in Table 2. Based on the permeability matching parameters ( $\eta$ and $\lambda$ ), the proppant pack embedment can be calculated. It is shown in Fig. 7 that the calculated proppant pack embedment ranges from about $3 \mathrm{~mm}$ to about 8 $\mathrm{mm}$ for the four samples studied. The embedment curves show different trend with the monolayer proppant embedment experimental data from Alramahi and Sundberg (2012) as shown in Section 2. The shape of embedment curve is controlled by $\lambda$ : the curve concaves to the stress axial when $\lambda>1$ (Fig. 7); the curve concaves to the embedment axial when $\lambda<1$ (Fig. 3 ); the curves becomes a straight line when $\lambda=1$. The power law model proposed is flexible to cope with different situations. In addition, the proppant embedment of the proppant pack is several times larger than the monolayer condition. More fundamental studies are warranted to further investigate the proppant embedment behaviour under different conditions.

In most unconventional reservoirs, gas is produced through pressure depletion. The effective stress increases with the reservoir depletion. The permeability would decrease with gas production. The permeability would decrease further at higher stress condition when the proppant embedment also becomes a dominate factor for the permeability change. The permeability change for hydraulic fractures is influenced by the combined effect of compaction and proppant embedment. The modelling results show that the model proposed could adequately describe this behaviour. However, improvement on the proppant embedment model is required when more data are available to reveal the proppant embedment behaviour under different circumstances, such as rock type, rock mechanical property, proppant type, proppant size, proppant concentration, stress condition and so on.

\section{Conclusions}

The proppant embedment in shale sample is modeled with the Hertz model and a proposed power law model. Since the embedment exceeds the limit of the Hertz assumption, the experimental data are better described by the power law relation between the embedment and the effective stress. Moreover, the power law model is flexible to model the different curvature shapes or trends of embedment curves by adjusting the power index $\lambda$.

By incorporating the power law correlation into an existing theoretical permeability model as a function of mean effective stress, a permeability model for the hydraulic fracture filled with proppant packs under combined effect of compaction and embedment was developed. The existing permeability model as a function mean effective stress can well describe the permeability change solely due to the compaction. With increasing stress level, the proppant embedment becomes another important influencing parameter for the permeability change due to fracture closure. The permeability drops for several times at higher stress conditions for the samples confined by the rock core slices (compaction and embedment) compared with 
those confined by steel platen (compaction and no embedment). The new model could adequately describe the permeability data and the existing model without considering the embedment would underestimate the permeability drop.

Although this study puts forward the theoretical basis of hydraulic permeability modelling under combined effect of compaction and embedment, more fundamental studies are required to investigate the contact behaviour between the proppant pack and the fracture face under various conditions. The permeability model could be further improved by introducing advanced proppant embedment correlations based on more experimental evidence.

\section{Acknowledgement}

The authors acknowledge the financial support from Science Foundation of China University of Petroleum, Beijing (No. 2462014YJRC060 and No.2462014YJRC059).

\section{Reference}

Alramahi, B., Sundberg, M.I., 2012. Proppant embedment and conductivity of hydraulic fractures in shales. The $46^{\text {th }}$ US Rock Mechanics/Geomechanics Symposium, Chicago, IL, Juen 24-27.

Chen, D., Pan, Z., Ye, Z., 2015. Dependence of gas shale fracture permeability on effective stress and reservoir pressure: Model match and insights. Fuel 139, 383-392.

Chen, D., Pan, Z., Ye, Z., Hou, B., Wang, D., Yuan, L., 2016. A unified permeability and effective stress relationship for porous and fractured reservoir rocks. Journal of Natural Gas Science and Engineering 29, 401-412.

Chen, D., Shi, J.Q., Durucan, S., Korre, A., 2014. Gas and water relative permeability in different coals: Model match and new insights. International Journal of Coal Geology 122, 37-49.

Fischer-Cripps, A.C., 2007. Introduction to contact mechanics. Second Edition, Springer, USA.

Fredd, C.N., McConnell, S.B., Boney, C.L., England, K.W., 2000. Experimental study of hydraulic fracture conductivity demonstrates the benefits of using proppants. SPE Rocky Mountain Regional/Low-Permeability Reservoirs Symposium and Exhibition, Denver, Colorado.

Gaurav, A., Dao, E.K., Mohanty, K.K., 2012. Evaluation of ultra-light-weight proppants for shale fracturing. Journal of Petroleum Science and Engineering 92-93, 82-88.

Holditch, S.A., 2013. Unconventional oil and gas resource development - Let's do it right. Journal of Unconventional Oil and Gas Resources 1-2, 2-8. 
Howarth, R.W., Ingraffea, A., Engelder, T., 2011. Should fracking stop? Extracting gas from shale increases the availability of this resource, but the health and environmental risks may be too high. Nature 477, 271-275.

Hughes J.D., 2013. A reality check on the shale revolution. Nature 494, 307-308.

Kassis, S.M., Sondergeld, C.H., 2010. Gas shale permeability: Effects of roughness, proppant, fracture offset, and confining pressure. International Oil and Gas Conference and Exhibition in China, Beijing, China.

Khanna, A., Kotousov, A., Sobey, J., Weller, P., 2012. Conductivity of narrow fractures filled with a proppant monolayer. Journal of Petroleum Science and Engineering 100, 9-13.

Lee, D.S., Elsworth, D., Yasuhara, H., Weaver, J.D., Rickman, R., 2010. Experiment and modelling to evaluate the effects of proppant-pack diagenesis on fracture treatments. Journal of Petroleum Science and Engineering 74, 67-76.

Oliver, W.C., Pharr, G.M., 1992. An improved technique for determining hardness and elastic modulus using load and displacement sensing indentation experiments. Journal of Materials Research 7, 1564-1583.

Parker, M.A., Glasbergen, G., van Batenburg, Weaver, J.D., Slabaugh, B.F., 2005. Highporosity fractures yield high conductivity. SPE Annual Technical Conference and Exhibition, Dallas, Texas.

Slatt, R.M., O’Brien, N.R., 2011. Pore types in the Barnett and Woodford gas shales: contribution to understanding gas storage and migration pathways in fine-grained rocks. AAPG Bulletin 95, 2017-2030.

Sone, H., Zoback, M.D., 2013. Mechanical properties of shale-gas reservoir rocks - Part 1: Static and dynamic elastic properties and anisotropy. Geophysics 78, d381-d392.

Suarez-Rivera, R., Burghardt, J., Edelman, E., Stanchits, S., Surdi, A., 2013. Geomechanics considerations for hydraulic fracture productivity. $47^{\text {th }}$ US Rock Mechanics/Geomechanics Symposium, American Rock Mechanics Association.

Walsh, J.B., 1981. Effect of pore pressure and confining pressure on fracture permeability. International Journal of Rock Mechanics and Mining Sciences 18, 429-435.

Wang, F.P., Reed, R.M., John, A., Katherine, G., 2009. Pore networks and fluid flow in gas shales. SPE Annual Technical Conference and Exhibition. New Orleans, Louisiana, USA, 4-7 October 2009.

Wen Q., Zhang S., Wang L., Liu Y., Li X., 2007. The effect of proppant embedment upon the long-term conductivity of fractures. Journal of Petroleum Science and Engineering 55, 221227. 


\section{Appendix}

The contact depth $h_{c}$ as shown in Fig. A1 is calculated by (Oliver and Pharr, 1992):

$$
h_{c}=h-G \frac{P}{S}
$$

where $G$ is a geometric constant of the indenter ( $G=0.72$ for a conical punch; $G=0.75$ for a paraboloid or a sphere punch; $G=1.00$ for a flat punch), and $S=d P / d h$ is defined as the slope of the upper portion of the unloading curve during the initial stages of unloading (also called the contact stiffness which is assumed as a constant, see Fig. A2).

Incorporating Eq. (9) into Eq. (A1), the contact depth can be related to the penetration depth for a sphere indenter:

$$
h_{c}=h-G \frac{P}{S}=\left(1-\frac{3 \alpha}{4 S} h^{m-1}\right) h
$$

As shown in Fig. A1, the following relation holds:

$$
a^{2}+\left(R-h_{c}\right)^{2}=R^{2}
$$

The correlation between effective stress and proppant embedment is obtained:

$$
\sigma_{e}=\frac{P}{\pi a^{2}}=\frac{\alpha h^{m}}{\pi\left[R^{2}-\left(R-h_{c}\right)^{2}\right]}
$$

When the proppant embedment is high, the contact depth $h_{c}$ gets close to $R$. Eq. (A4) can be further reduced to a power law relationship:

$$
h=\sqrt[m]{\frac{\pi R^{2}}{\alpha} \sigma_{e}}=\eta\left(\sigma_{e}\right)^{\lambda}
$$

where $\eta$ is a function of $m, \alpha$ and $R$, while $\lambda$ is the reciprocal of $m$. 
Table 1 Mechanical properties of the rocks used (data are collected from Wen et al., 2007)

\begin{tabular}{cccc}
\hline Rock type & Density $\left(\mathrm{g} / \mathrm{cm}^{3}\right)$ & Elastic modulus, E (GPa) & Poisson's ratio, $v$ \\
\hline Siltstone & 2.57 & 22.18 & 0.35 \\
\hline Conglomerate & 2.69 & 19.39 & 0.19 \\
\hline Dolomitic mudstone & 2.68 & 12.76 & 0.32 \\
\hline
\end{tabular}

Table 2 Parameters used in matching permeability data for proppant pack

\begin{tabular}{cccccc}
\hline Proppant & Mesh & $c_{p 0}\left(\mathrm{MPa}^{-1}\right)$ & $\alpha\left(\mathrm{MPa}^{-1}\right)$ & $\eta$ & $\lambda$ \\
\hline $1 \#$ & $20 / 40$ & 0.0036 & -0.022 & $2.2 \mathrm{e}-5$ & 2.6 \\
\hline $2 \#$ & $20 / 40$ & 0.0033 & -0.016 & $1.3 \mathrm{e}-9$ & 4.8 \\
\hline $1 \#$ & $30 / 60$ & 0.0020 & -0.028 & $2.1 \mathrm{e}-5$ & 2.8 \\
\hline $2 \#$ & $30 / 60$ & 0.0011 & -0.041 & $1.6 \mathrm{e}-5$ & 3.1 \\
\hline
\end{tabular}




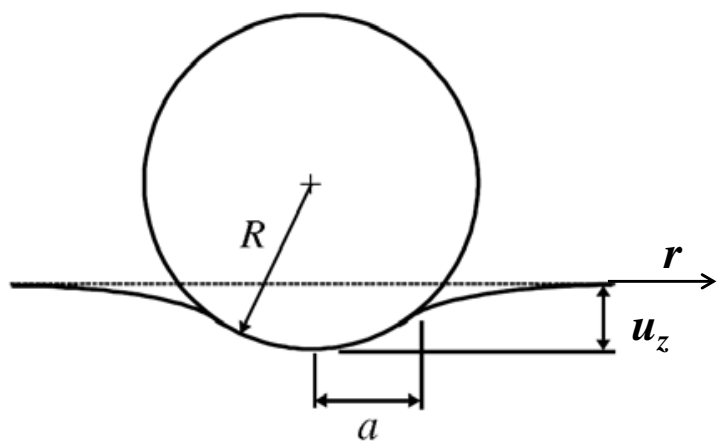

Fig. 1 Hertz contact problem between a rigid sphere and an elastic semi-infinite half-space

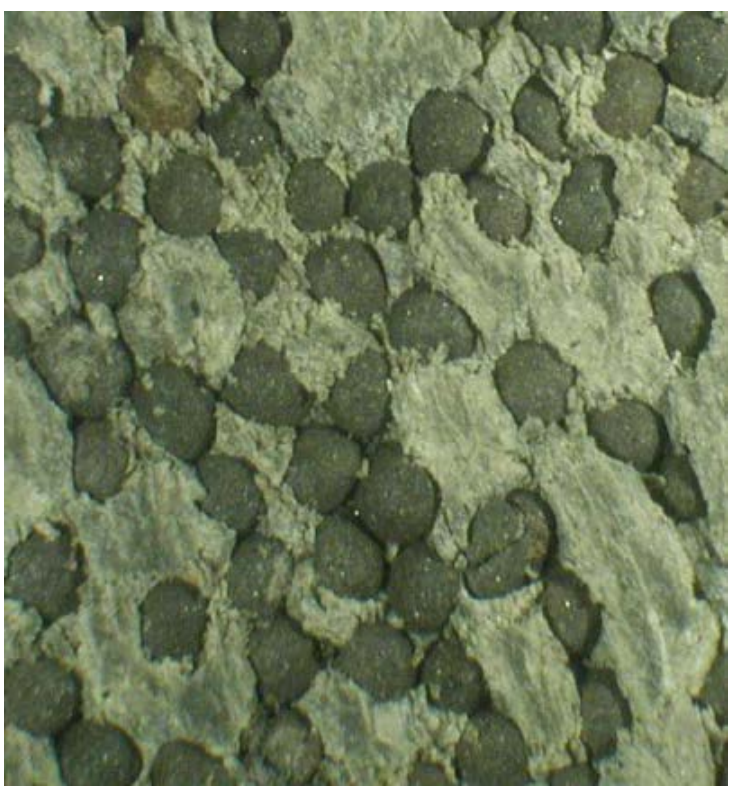

(a) Low stiffness sample

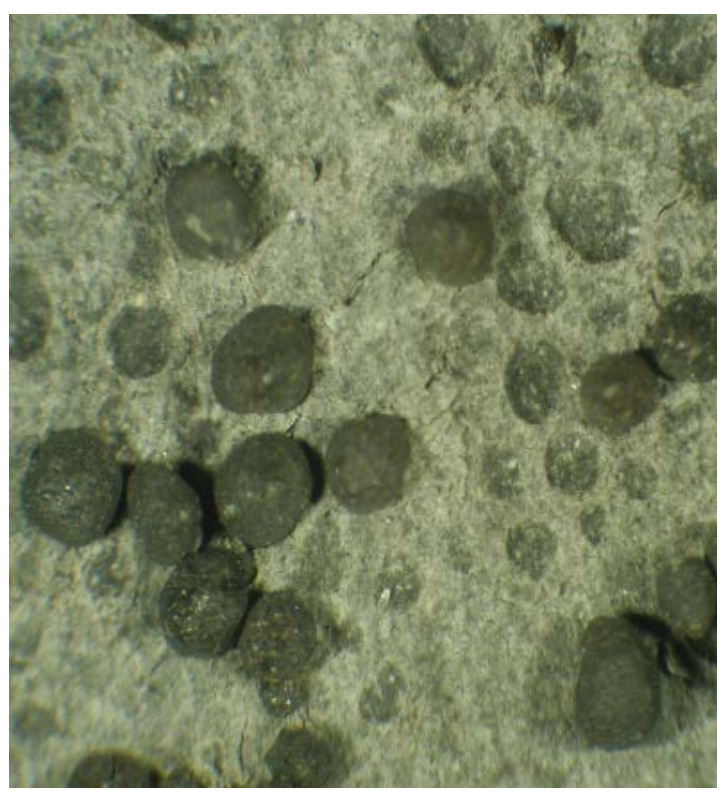

(b) High stiffness sample

Fig. 2 Pictures of proppant embedment (source: Alramahi and Sundberg, 2012: the low stiffness sample may have 52\% clay and the Young's modulus is about $1.79 \mathrm{GPa}$; the high stiffness sample may have $10 \%$ clay and the Young's modulus is about $42.54 \mathrm{GPa}$ ) 


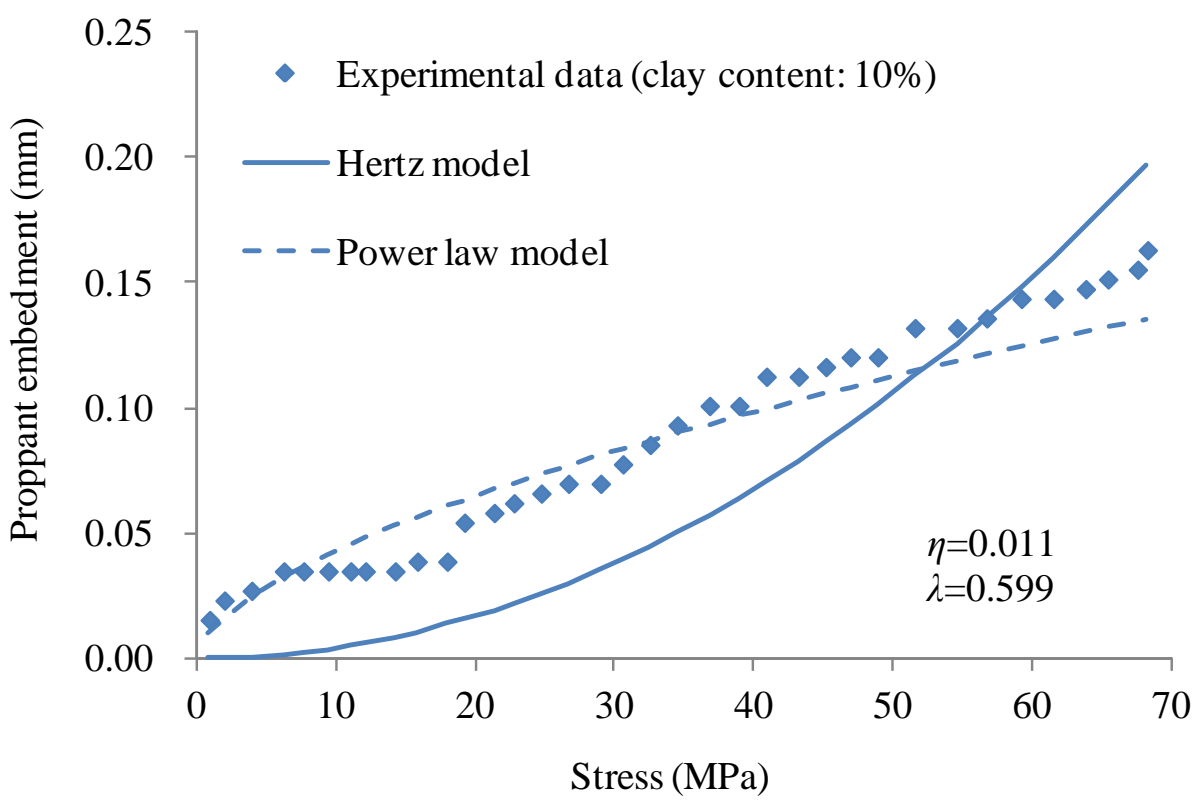

(a) Shale sample with $10 \%$ clay content

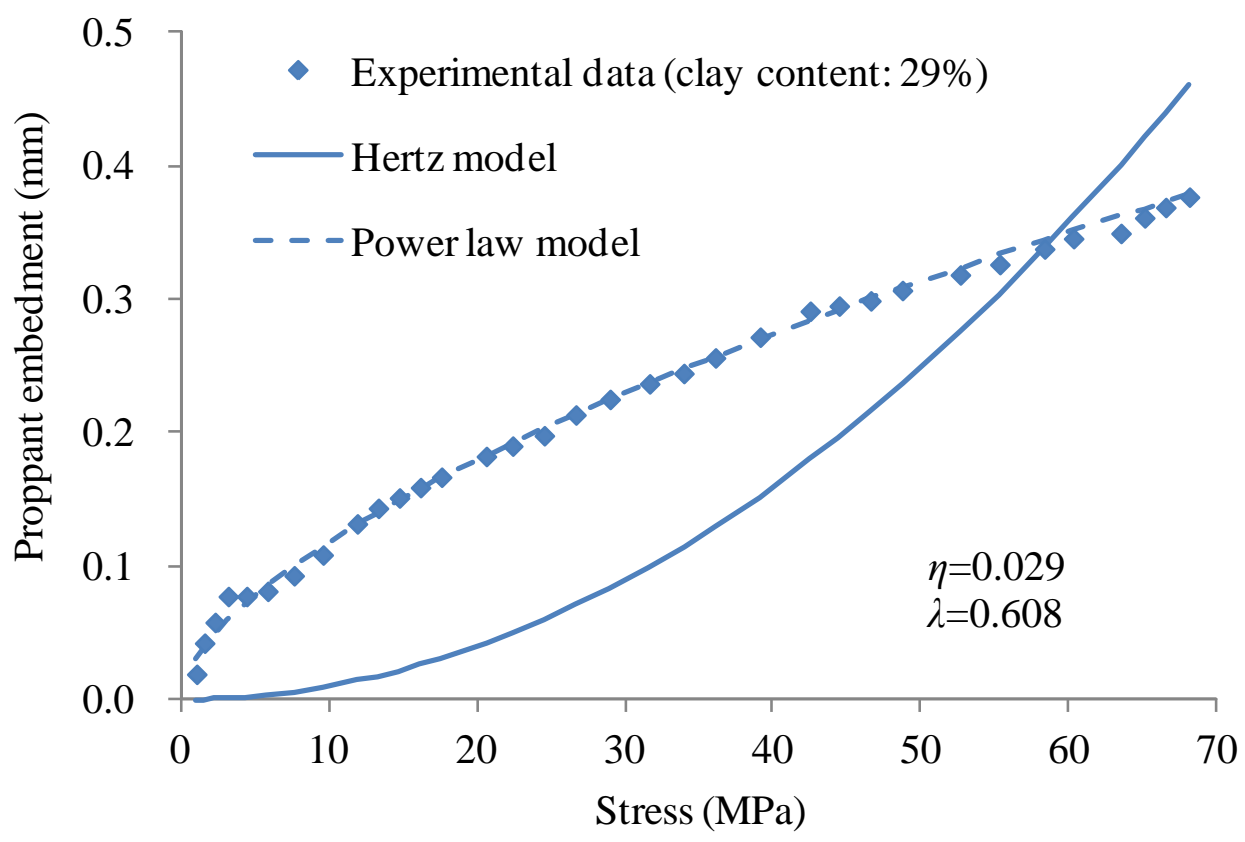

(b) Shale sample with $29 \%$ clay content 


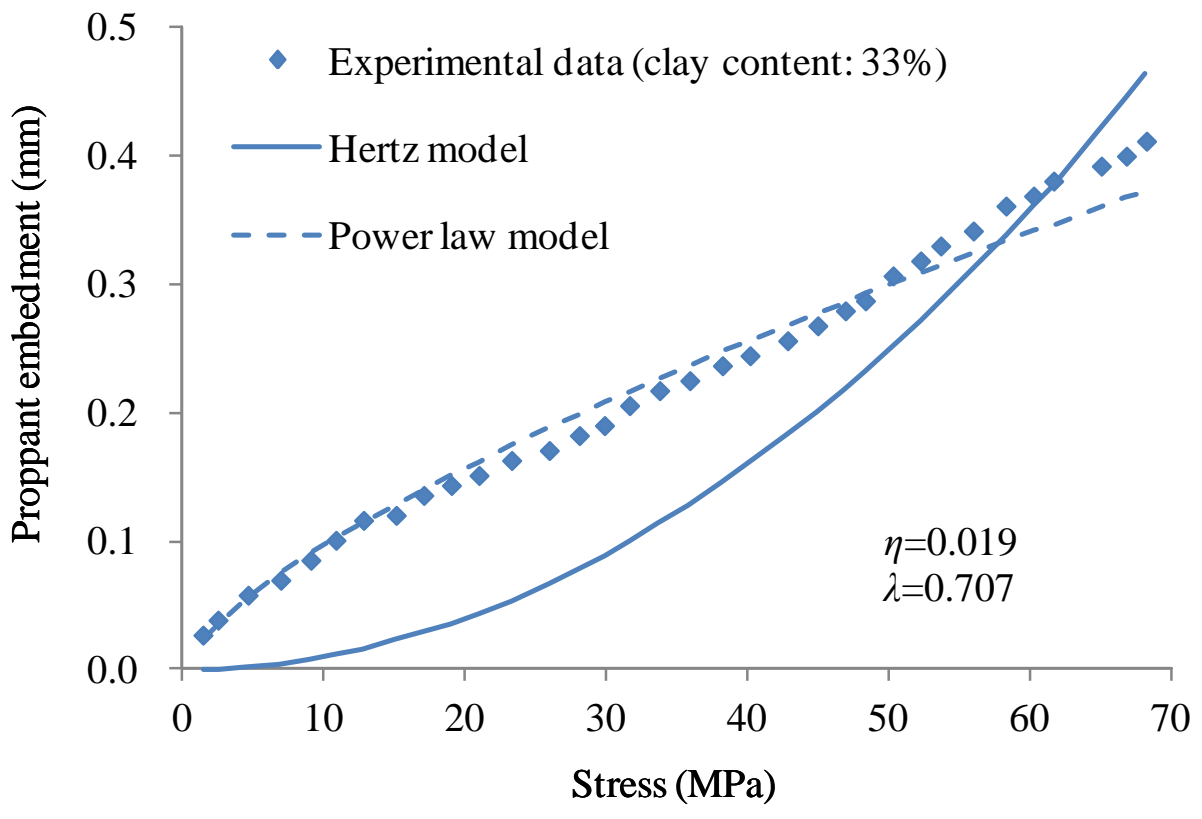

(c) Shale sample with 33\% clay content

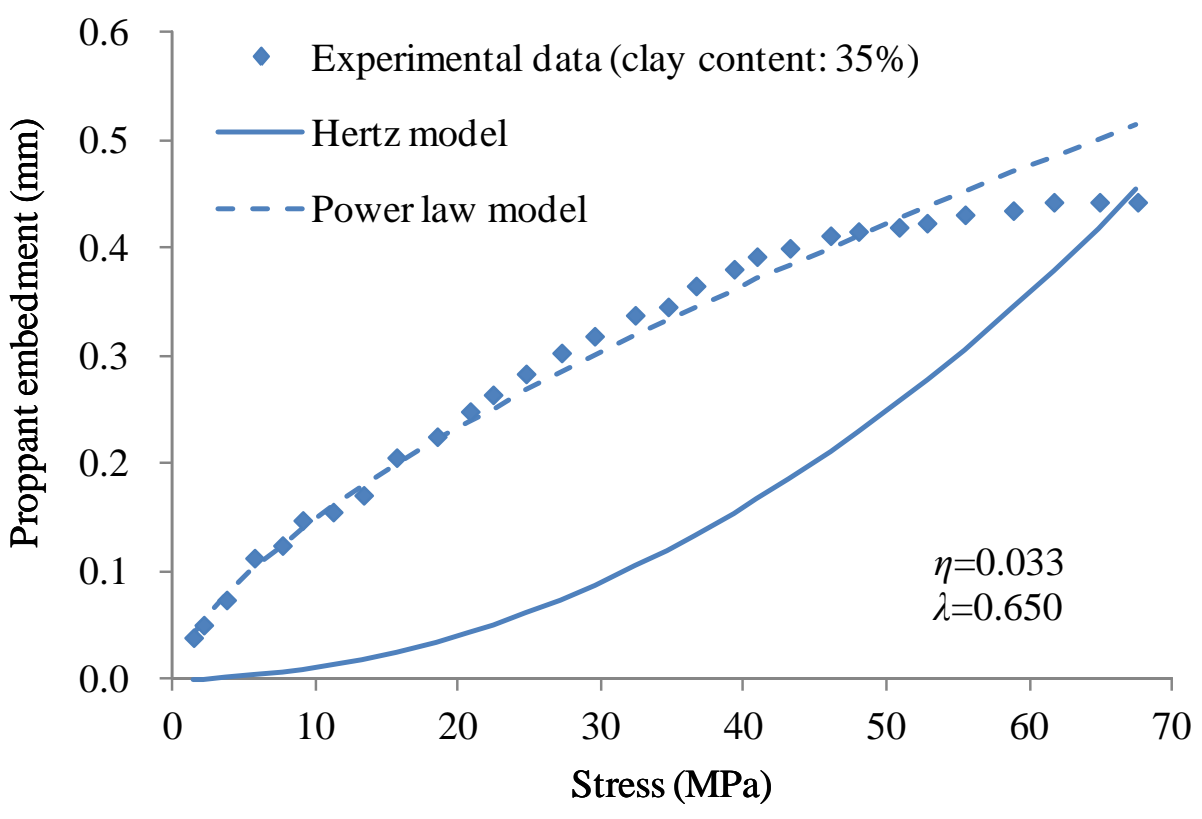

(d) Shale sample with 35\% clay content 


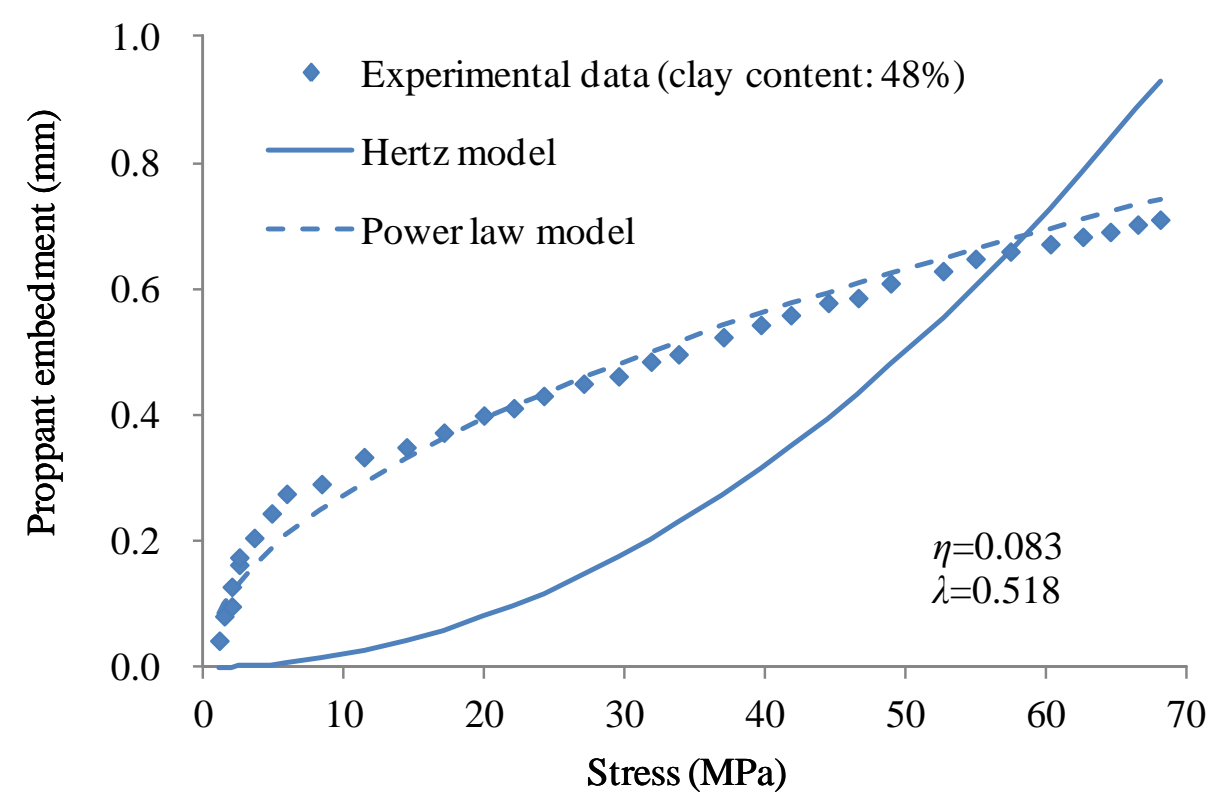

(e) Shale sample with $48 \%$ clay content

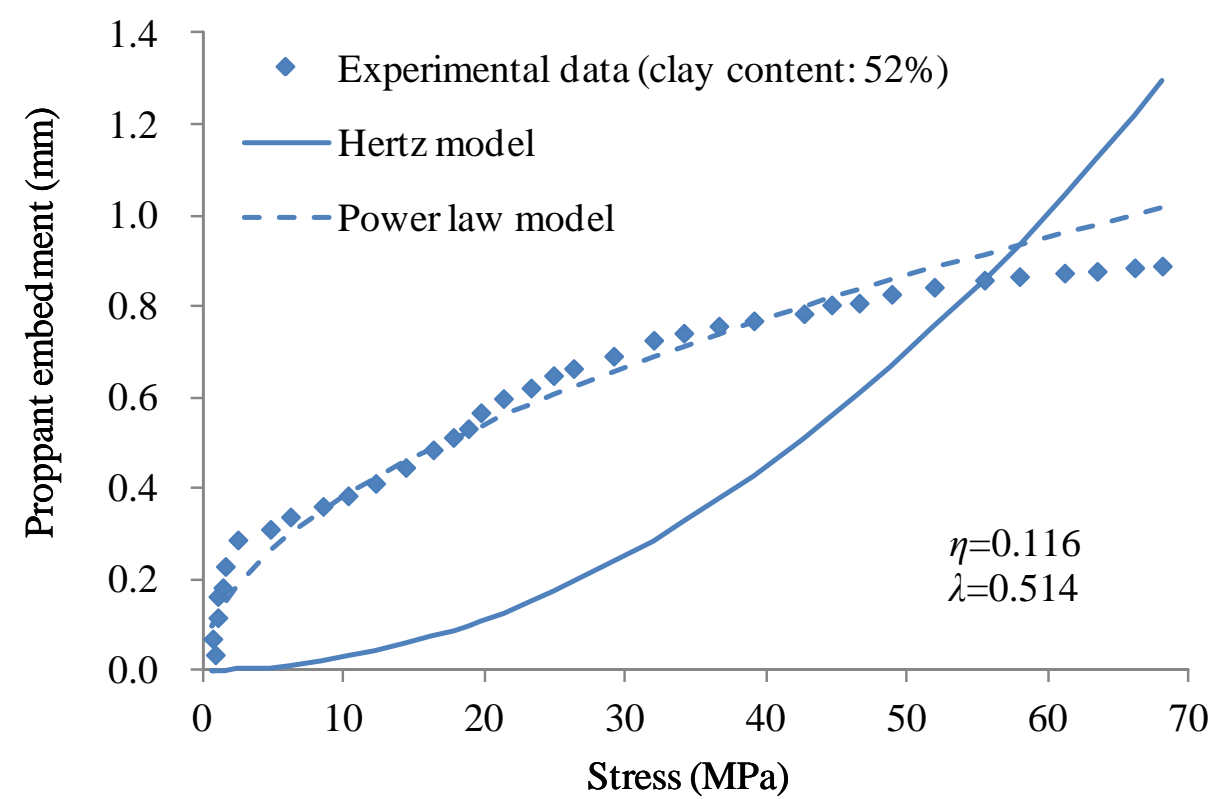

(f) Shale sample with $52 \%$ clay content

Fig. 3 Matching proppant embedment in shales with different clay contents using the Hertz model and the power law model 


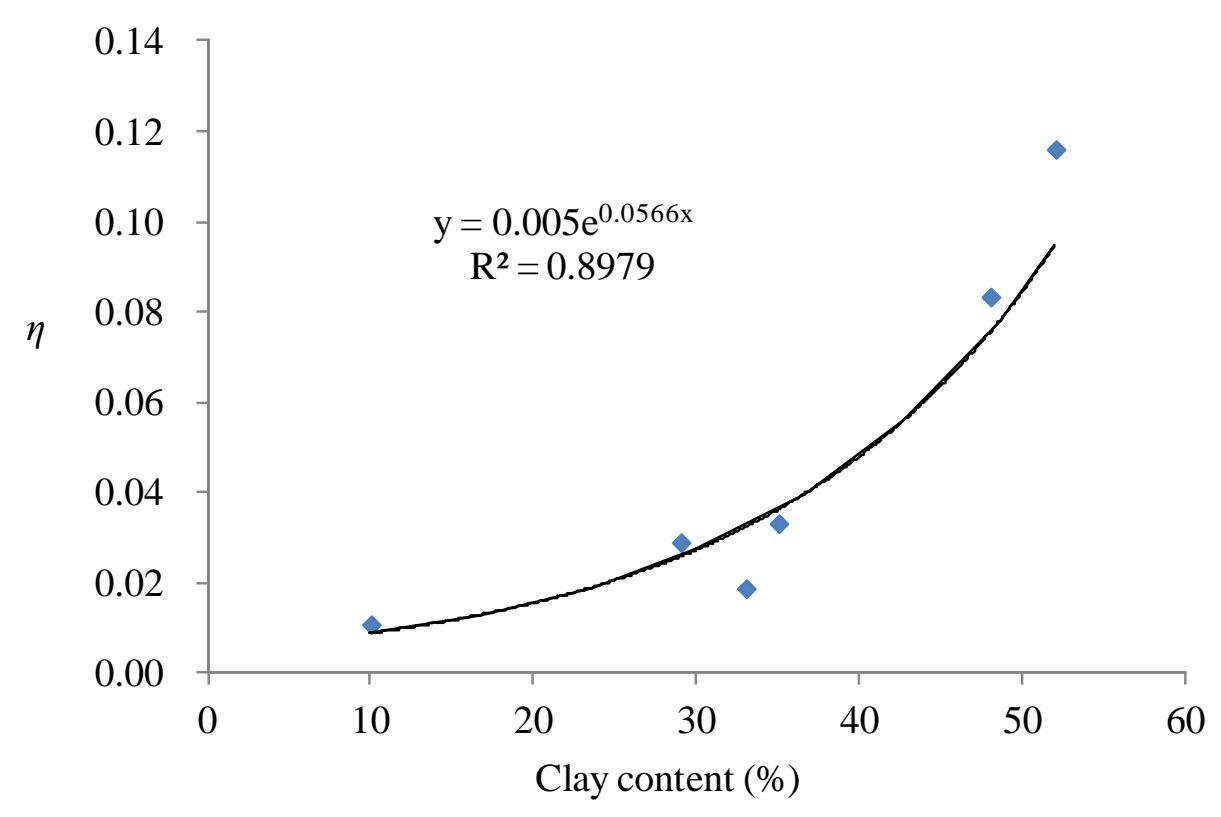

Fig. 4 Correlation between $\eta$ and clay content

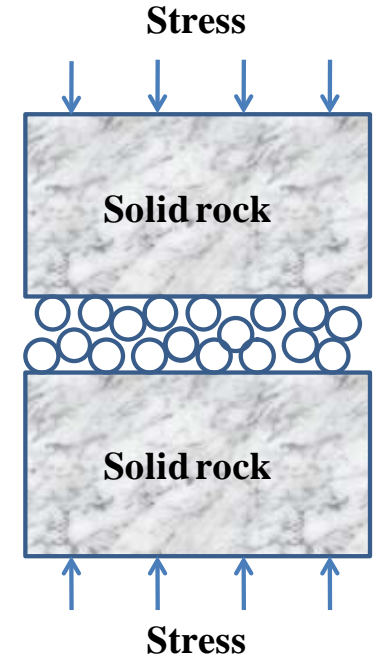

(a) Before embedment
Stress

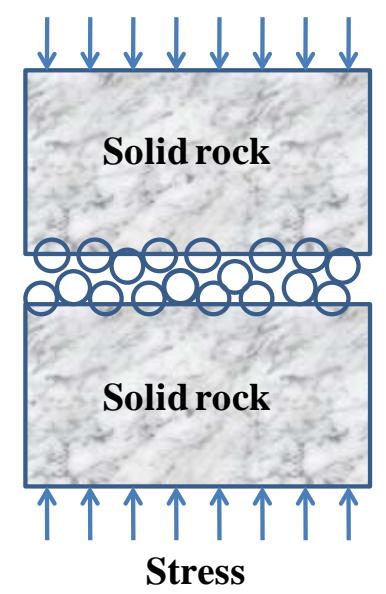

(b) After embedment

Fig. 5 Effect of proppant embedment on hydraulic fracture closure 


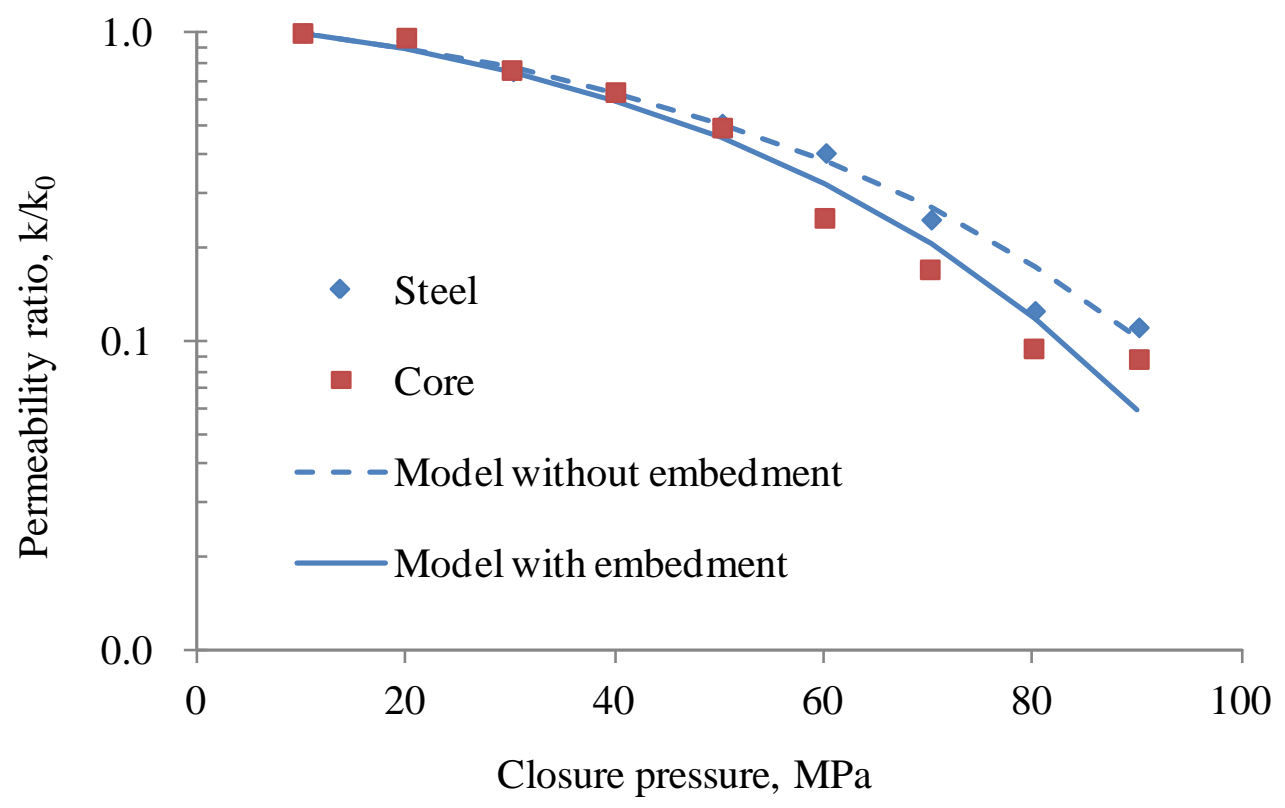

(a) Mesh 20/40, 1\#

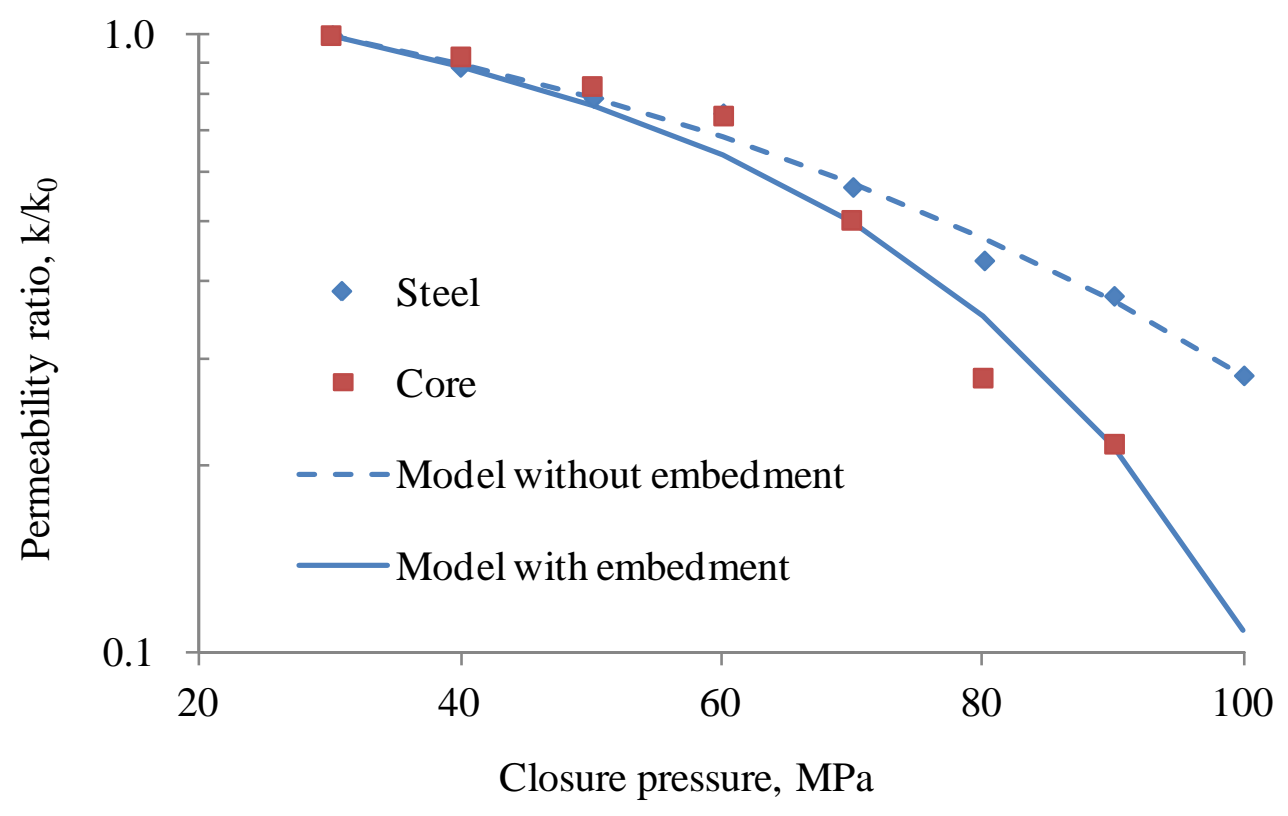

(b) Mesh 20/40, 2\# 


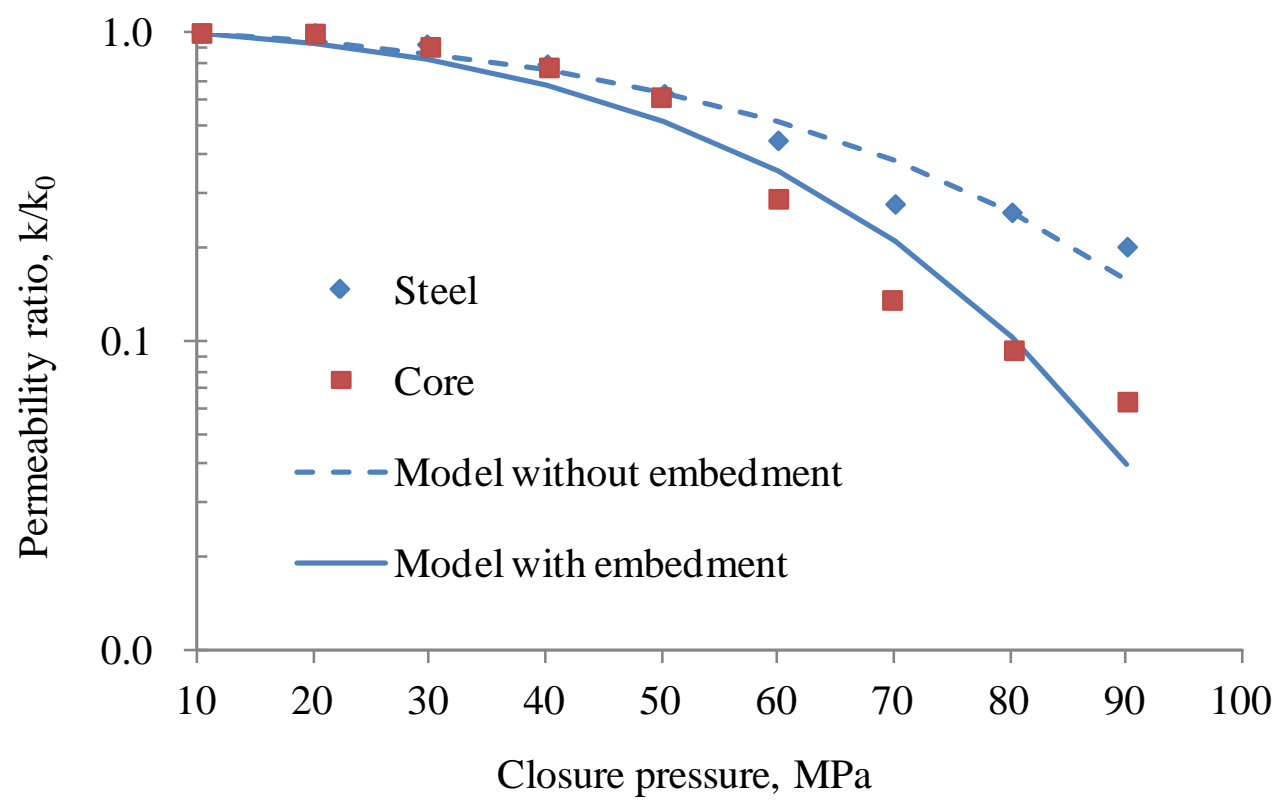

(3) Mesh 30/60, 1\#

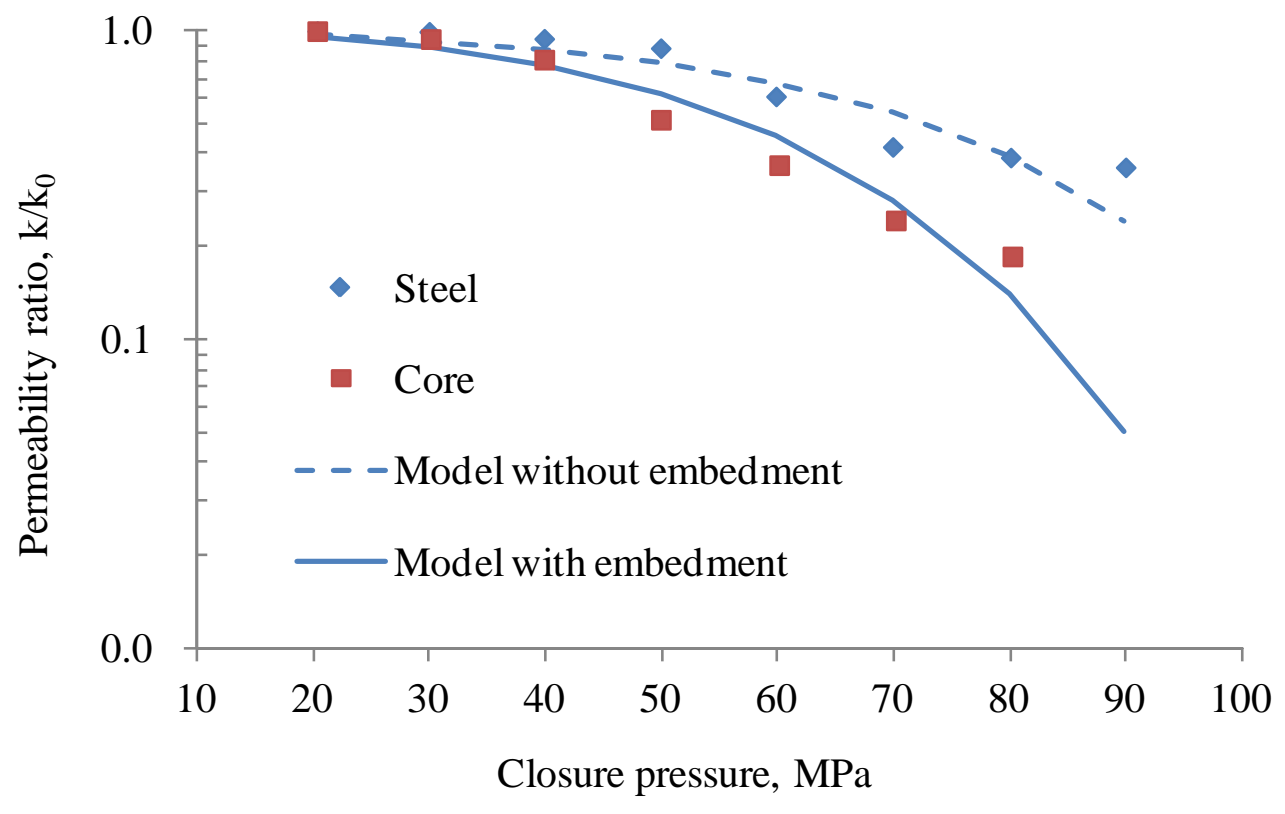

(4) Mesh 30/60, 2\#

Fig. 6 Model match the permeability data for steel and core confined proppant pack 


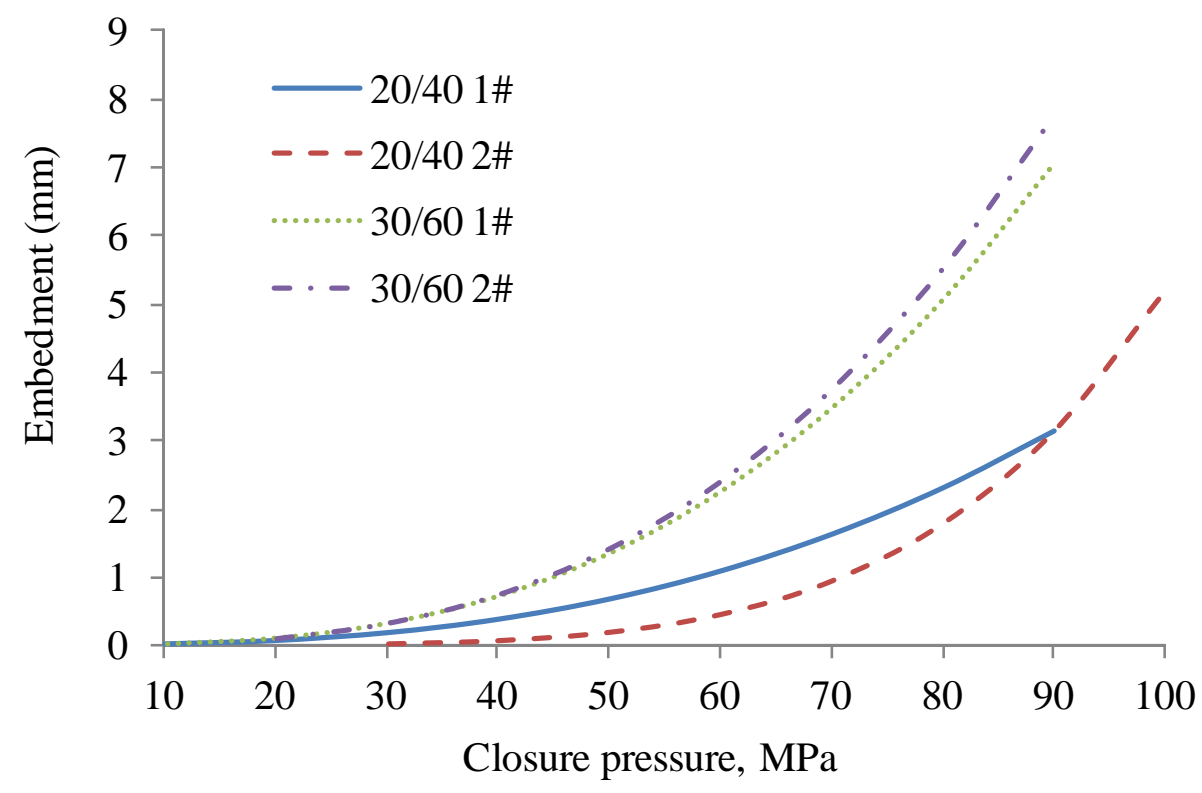

Fig. 7 Calculated embedment on basis of the parameters ( $\eta$ and $\lambda$ ) obtained from matching the permeability change (Table 2 )

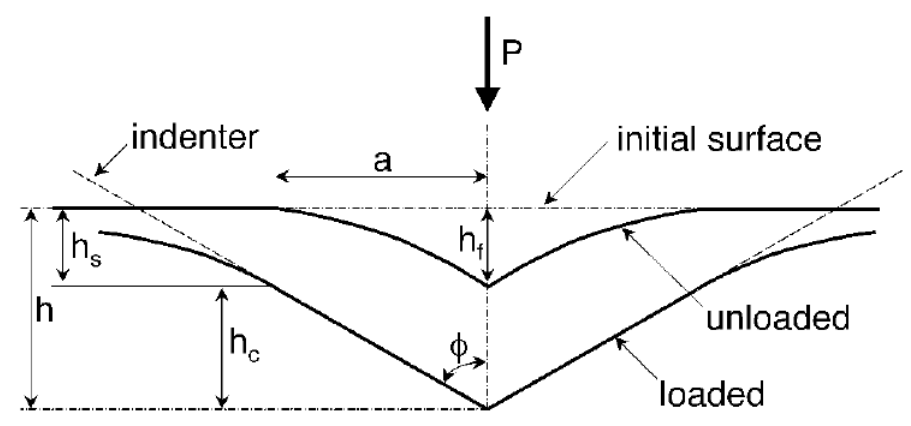

Fig. A1 Contact behaviour between indenter and specimen (Source: Oliver and Pharr, 1992) 


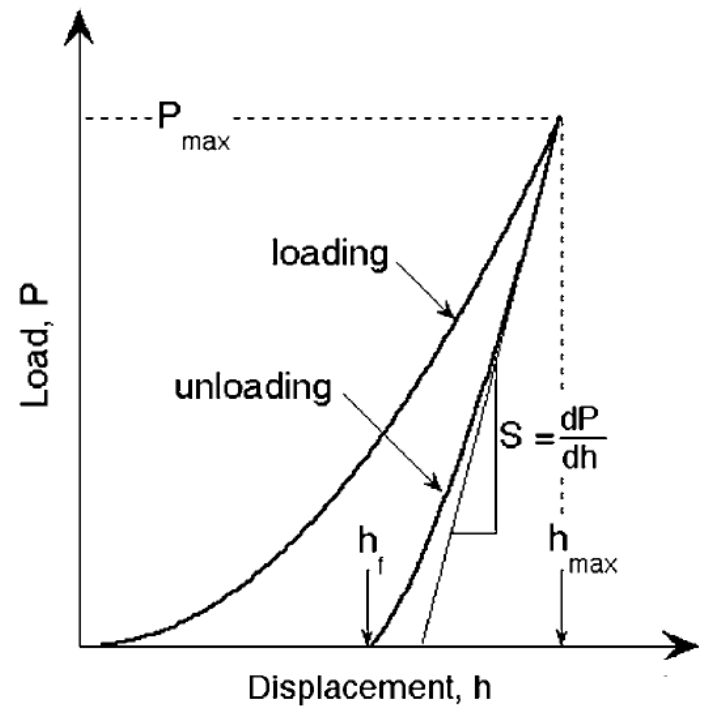

Fig. A2 Schematic of indentation load and displacement correlation (Source: Oliver and Pharr, 1992) 